\title{
Regional differentiation of ecological conservation and its zonal suitability at the county level in China
}

\author{
HUANG Lin ${ }^{1}$, ZHENG Yuhan ${ }^{1,2}$, XIAO Tong ${ }^{3}$ \\ 1. Key Laboratory of Land Surface Pattern and Simulation, Institute of Geographic Sciences and Natural \\ Resources Research, CAS, Beijing 100101, China; \\ 2. University of Chinese Academy of Sciences, Beijing 100049, China; \\ 3. Satellite Environment Center, Ministry of Environmental Protection, Beijing 100094, China
}

\begin{abstract}
China's investments, financial incentives and deductions in terms of ecological conservation are based at the county level. Therefore, the monitoring and assessment of the effects of ecological conservation at the county level is important to provide a scientific basis for the assessment of the ecological and environmental quality at the county scale. This paper quantitatively estimated the dynamics of high-quality ecosystems and vegetation coverage over the past 15 years, and their relationships with the number of ecological conservation programs at the county level were analyzed. Then, the effects of ecological conservation measures on ecological changes at the county level and their regional suitability were assessed and discussed. The results showed that counties with a percentage of high-quality ecosystems greater than $50 \%$ were primarily distributed in northeastern China, southern subtropical China and the southeastern Qinghai-Tibet Plateau, and those with a percentage lower than $20 \%$ were mostly distributed in northwestern China, the southwestern karst region and the North China Plain. In recent decades, ecological conservation has focused on ecologically fragile regions; more than five ecological conservation programs have been implemented in most counties of the Three River Source Region in Qinghai Province, southeastern Tibet, western Sichuan, the Qilian Mountains, southern Xinjiang and other western regions, while only one or zero have been implemented in the eastern coastal area of China. Over the past 15 years, the proportional area of high-quality ecosystems has increased in approximately $53 \%$ of counties. The vegetation coverage of counties in the Loess Plateau, Huang-Huai-Hai Plain, Beijing-Tianjin-Hebei (Jing-Jin-Ji), Sichuan-Guizhou-Chongqing, and Guangdong-Guangxi provincial-level areas has increased significantly. However, it decreased in northern Xinjiang, central Tibet, central and eastern Inner Mongolia, the Yangtze River Delta and other regions. The relationships between the numbers of ecological conservation programs and the indicators of ecosystem restoration response, such as high-quality ecosystem and vegetation coverage, do not show positive correlations. These results suggest that ecological conservation programs should be planned and implemented according to the distribution patterns of high-quality ecosystems and that restoration measures such as afforestation should follow natural principles and regional differentiation under the background of climate change.
\end{abstract}

Received: 2017-07-21 Accepted: 2017-08-28

Foundation: National Natural Science Foundation of China, No.41371019; National Science \& Technology Pillar Program, No.2013BAC03B00

Author: Huang Lin (1981-), PhD, specialized in land use change and its ecological effects. E-mail: huanglin@igsnrr.ac.cn 
Keywords: ecological conservation; high-quality ecosystem; regional differentiation; suitability assessment; county scale; China

Ecosystem degradation and biodiversity loss accompanied by industrialization, urbanization and agricultural modernization have attracted widespread attention (Liu and Diamond, 2005; Zhang and Zhao, 2007; Fu, 2010; Liu et al., 2014). To reverse the deterioration of the ecological environment, China began to implement the Three-North Shelter Forest Program (TNSF) in the 1970s, and a series of major ecological protection and construction programs have subsequently been carried out since 2000, such as the Natural Forest Resources Protection (NFRP), Grain for Green Program (GFGP), Shelter Forest in the Yangtze River Basin (SF-YR) and Shelter Forest in the Pearl River Basin (SF-PR), Returning Rangeland to Grassland (RRG), Wetland Conservation (WC), and Wildlife Protection and Nature Reserve Construction (WPNRC). According to statistics, the total investment in ecological programs has been more than 1.3 trillion yuan. With the implementation of the series of ecological programs, the situation of sustained degradation of ecosystems in China has been curbed in some areas, and the ecological environment in the area where the programs have been implemented has significantly improved (SFA-PRC, 2008, 2016a, 2016b), forest area and vegetation coverage have significantly increased (Wang et al., 2010; Li et al., 2012; Huang et al., 2016), degraded grassland has been restored (Liu et al., 2008; Shao et al., 2013; Shao et al., 2017), the expansion rate of desertified land has been effectively controlled (Wang et al., 2004; Zhuo et al., 2007), the area of soil erosion has declined, and the soil and water conservation capacity of some areas experiencing soil erosion has been significantly enhanced (Wang et al., 2012; Deng et al., 2014; Wang et al., 2015). However, China's ecological deterioration trend has not yet been fundamentally reversed, the contradiction between ecological protection and economic development is still outstanding, and the ecological security situation is still grim (MEP-PRC, 2016).

Since the 1950s, ecological protection measures have been evaluated from the different aspects of ecological, economic and social benefits (Li and Zhai, 2002). In the 1990s, China constructed an evaluation index system for the major ecological programs of the Three-North Shelter Forest Program, Natural Forest Resources Protection, and Grain for Green Program to assess the ecological benefits of programs by applying site monitoring and comparison, remote sensing observation and inversion (SFA-PRC, 2008, 2016a, 2016b). However, due to the lack of long-term temporal and spatial information on ecosystem changes and the integrated technical methods of project monitoring and evaluation, we do not have a quantitative understanding of the ecosystem changes since the implementation of large-scale ecological programs. It is difficult to conduct a quick and scientific evaluation of the ecological effects of the programs, and there is a lack of targeted understanding regarding the project layouts and policy designs of ecological conservation efforts in the future (Shao et al., 2017; MEP-PRC and CAS, 2017). Therefore, there is an urgent need for all kinds of ecological programs to carry out systematic, comprehensive and accurate assessments of the ecological effects through third-party organizations.

However, the planning scope and actual investment of ecological conservation programs have considered the county as the basic unit. Because the spatial distribution of a project is not considered during planning, it is difficult to obtain the specific scope of the program at 
the macro scale, and it is difficult to distinguish the role of climate change versus the contribution of ecological programs or even the contribution of a certain program in response to regional ecosystem changes. At the same time, the assessment of the performance of local governments in the past only involved Gross Domestic Product (GDP) and did not consider the ecological environment or even simple assessment indicators. In recent years, the ecological GDP or Grass Ecosystem Product have become new measures to evaluate performance, and differential assessment mechanisms have been implemented according to the main functions in terms of impoverished or ecologically fragile or healthy counties (Liu et al., 2011). Many studies have been carried out to evaluate the quality of the ecological environment at the county scale and have attempted to apply such assessments to evaluate performance at the county level (Liu et al., 2010; Liu et al., 2012; Li et al., 2014).

Since 2011, the central government has annually monitored and evaluated the quality of the ecological environment of the counties included in the key ecological function area and reduced or increased their financial transfer payment funds according to the degree of change in the ecological environment (MF-PRC, 2011). Therefore, we need to understand the interannual variability in ecosystem conditions at the county level to improve ecological restoration and ecological conservation programs. At the national or regional scale, what is the regional suitability of ecological conservation programs and measures? Do those programs and measures follow the suitability of the zone? In addition, what problems should be addressed in future program design and the spatial layout and specific implementation of ecological programs? Therefore, determining how to carry out the monitoring and evaluation of ecosystem changes and ecological conservation effects at the county scale has become an urgent problem to be solved. This study can supply the reference method for monitoring and evaluating the quality of the ecological environment at the county scale and provide a scientific basis for the further implementation and continued planning of ecological programs.

\section{Data and methods}

\subsection{Data collection and processing}

In this paper, the ecological conservation activities of China mainly refer to the national key ecological programs, which consist of TNSF, NFRP, GFGP, SF-YR, SF-PR, WPNRC, RRG, Beijing and Tianjin Sand Source Control (BTSSC), Ecological Conservation and Restoration in the Three-River Source Region (ECR-TRSR), Tibet Ecological Security Conservation (TESC), and Comprehensive Control of Rocky Desertification in Karst Area (CCRDK). In addition, the national financial transfer payments for ecosystem function conservation areas (EFCAs) were also considered. Figure 1 shows the spatial distribution of these programs at the county scale. The numbers of ecological conservation activities implemented in each county are shown.

The land use and land cover change (LULCC) datasets for China in 2000 and 2015 with a spatial resolution of $100 \mathrm{~m}$ were applied (Liu et al., 2014), which were obtained by manual interpretation based on Landsat TM/ETM+ and CBERS (China \& Brazil Earth Resource Satellites) images. These datasets were divided into 6 primary land use and land cover types, consisting of cropland, forest land, grassland, wetland, built-up land and unused land. The 6 
primary types were further divided into 25 secondary land use and land cover types.

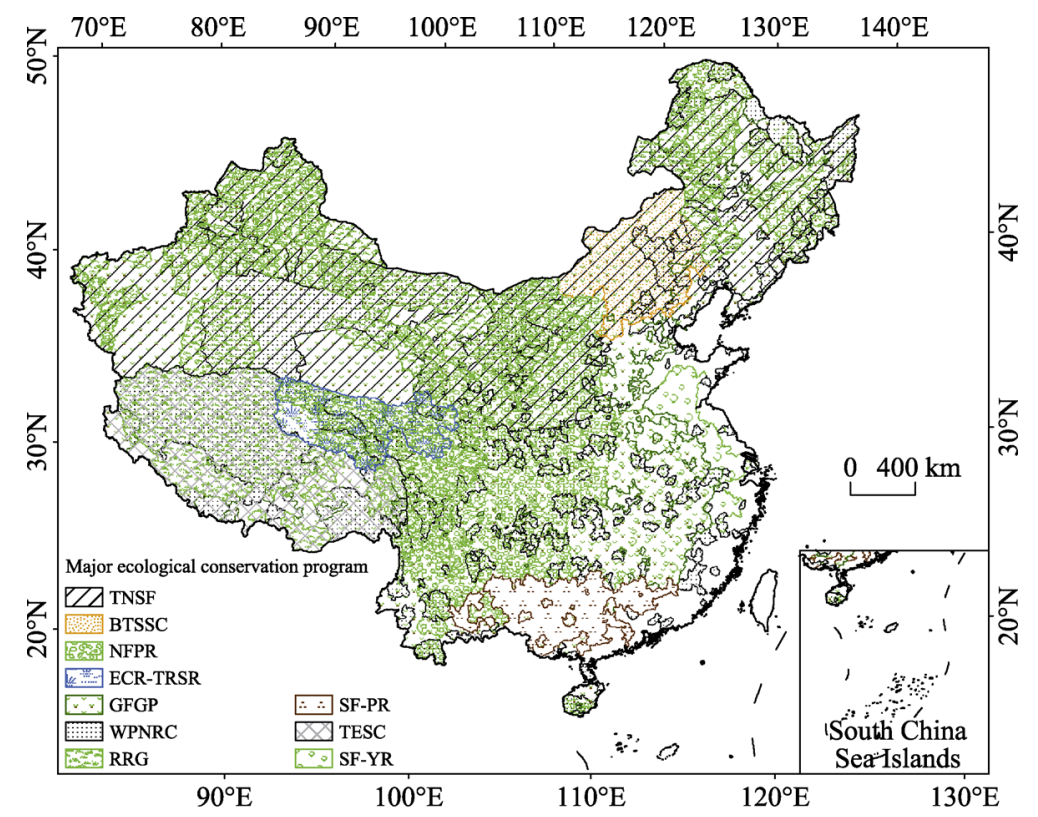

Figure 1 The distribution of ecological conservation programs at the county level in China

Normalized Difference Vegetation Index (NDVI) products from the Moderate-resolution Imaging Spectroradiometer (MODIS) with $1 \mathrm{~km}$ spatial resolution from 2000 to 2015 were collected. Sixteen-day NDVI datasets with continuous time series were obtained using the maximum-value composites (MVC) method. The data were processed using mosaics and filtering. It was applied to estimate the vegetation coverage according to the theory of the dichotomous pixel model, which means that the NDVI value of one pixel represents the contribution from the green vegetation and the contribution from the vegetation-free area. The formula is as follows:

$$
F_{c}=\frac{N D V I-N D V I_{\text {soil }}}{N D V I_{\text {veg }}-N D V I_{\text {soil }}}
$$

where $F_{c}$ is the vegetation coverage, and $N D V I_{\text {veg }}$ and $N D V I_{\text {soil }}$ are the NDVI values of the grids full of green vegetation and vegetation-free areas, respectively. The two grids were determined based on the land use and land cover datasets.

Data representing the precipitation, maximum and minimum air temperature, sunshine hours, wind speed at $2 \mathrm{~m}$, and relative humidity observed at 740 national meteorological stations were downloaded from China Meteorological Data Service Center (http://data.cma.cn/), quality controlled and interpolated in a $1 \mathrm{~km}$ spatial grid using the ANUSPLIN interpolation method and applying the DEM as a covariate. The potential evapotranspiration was calculated using the FAO56-Penman-Monteith model that was improved in 1998 (Allen et al., 1998), and the wetting index $\left(I_{m}\right)$ was calculated based on the Thornthwaite method (Thornthwaite, 1948).

$$
I_{m}=100 \times\left(\frac{P}{E T_{0}}-1\right)
$$




$$
E T_{0}=\frac{0.408 \Delta\left(R_{n}-G\right)+\gamma \frac{900}{T+273} U_{2}\left(e_{s}-e_{a}\right)}{\Delta+\gamma\left(1+0.34 U_{2}\right)}
$$

where $E T_{0}$ is the annual potential evapotranspiration $(\mathrm{mm}), P$ is the annual total precipitation $(\mathrm{mm}), R_{n}$ is the surface net radiation $\left(\mathrm{MJ} \cdot \mathrm{m}^{-2} \cdot \mathrm{d}^{-1}\right), G$ is the soil heat flux density $\left(\mathrm{MJ} \cdot \mathrm{m}^{-2} \cdot \mathrm{d}^{-1}\right), T$ is the daily average temperature $\left({ }^{\circ} \mathrm{C}\right), U_{2}$ is the wind speed at $2 \mathrm{~m}\left(\mathrm{~m} \cdot \mathrm{s}^{-1}\right), e_{s}$ and $e_{a}$ are the saturated and actual vapor pressure, respectively $(\mathrm{kPa}), \Delta$ represents the slope of the saturated vapor pressure and temperature curve $\left(\mathrm{kPa}^{\circ}{ }^{\circ} \mathrm{C}^{-1}\right)$, and $\gamma$ is a constant of the wet and dry table $\left(\mathrm{kPa}^{\circ} \mathrm{C}^{-1}\right)$.

According to the range of $I_{m}$, the climatic zone are divided into arid $\left(I_{m}<-66.7\right)$, semi-arid $\left(-66.7<I_{m}<-33.3\right)$, semi-humid $\left(-33.3<I_{m}<0\right)$, humid $\left(0<I_{m}<20\right)$, and moist humid $\left(I_{m}>20\right)$.

\subsection{Study methods}

In this study, the county (city, county, and banner) was applied as the basic evaluation unit. We analyzed the changes in high-quality ecosystem and vegetation coverage at the county scale over the past 15 years and quantitatively determined the changes in ecosystem status. Then, the relationships between the numbers of ecological conservation programs and ecosystem changes were explored. Finally, the regional differentiation in the ecological effectiveness of conservation programs was investigated, and the regional suitability of conservation measures was discussed.

The high-quality ecosystem in this study was defined as including natural forest and plantations with a canopy density of more than $30 \%$, shrubs with a canopy density of more than $40 \%$ and a height less than $2 \mathrm{~m}$, grasslands with a coverage of more than $50 \%$, flooded wetlands and inland swamps. Within each county, the percentage of high-quality ecosystems and the percentage of high-quality ecosystem changes over the past 15 years based on the total area of high-quality ecosystems were statistically analyzed. The trends in the change in vegetation coverage during 2000-2015 were analyzed by the least squares method, and the annual rate of change over the past 15 years was statistically analyzed at the county scale.

The significance level of the trends was statistically evaluated using the correlation coefficient. The correlations between the numbers of ecological conservation programs and the proportional area of high-quality ecosystems as well as the annual rate of change in vegetation coverage were determined. Based on the wet index, which reflects changes in water and heat conditions, the regional suitability of afforestation, grassland planting and enclosures in different climate zones was analyzed.

\section{Results}

\subsection{Regional differentiation in high-quality ecosystems at the county scale}

The high-quality ecosystems are mainly distributed in the northeastern temperate monsoon climate zone and the southern subtropical regions (Figure 2). In northeastern China, from Xiao Hinggan to the Changbai Mountains, the proportional area of high-quality ecosystems of a county's total terrestrial area is more than $50 \%$ in most counties, with forest coverage over $30 \%$, which forms a natural barrier in this region. In the eastern part of Inner Mongolia 
located in the south of Da Hinggan, high-quality ecosystems in most counties account for more than $50 \%$, with concentrated forests, a high coverage of grasslands and a large number of wetlands. The middle part of Inner Mongolia is dominated by grasslands with high coverage, and with high-quality ecosystems composing more than $20 \%$ of the total area. In northwestern China, which is dominated by low-coverage grasslands and desert, the proportional area of high-quality ecosystems in most counties is less than $20 \%$, and just one-fourth of counties have a percentage of high-quality ecosystems exceeding $20 \%$. Only five of the counties have a percentage of high-quality ecosystems exceeding $50 \%$, mainly forests and high-coverage grassland distributed in the Tianshan Mountains and Qilian Mountains.

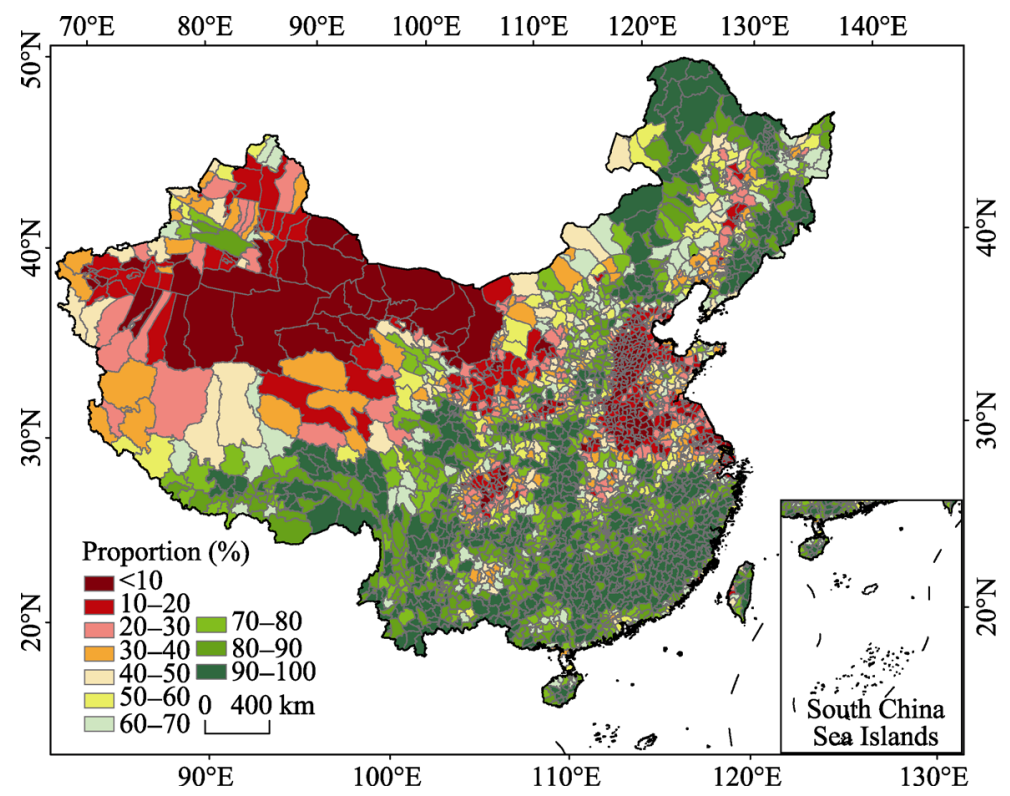

Figure 2 The zonal distribution pattern of China's high-quality natural ecosystems

Southern subtropical China is dominated by forests, and more than two-thirds of the counties have a percentage of high-quality ecosystems above $50 \%$. The percentage of highquality ecosystems in the southwestern karst region was lower, ranging from approximately $10 \%$ to $20 \%$. In areas where concentrated forests are distributed in the Qinling-Daba Mountains, southwestern Sichuan and Yunnan provinces, and northern Guangxi Zhuang Autonomous Region, the percentage of high-quality ecosystems is higher, accounting for more than $70 \%$ in most of the counties. However, on the North China Plain and in Jiangsu and Zhejiang provinces, the percentages of high-quality ecosystems are almost less than $10 \%$ due to the high level of urbanization and rapidly expanding construction land.

On the Qinghai-Tibet Plateau, grasslands are the most typical and widely distributed ecosystems. The number of counties with a percentage of high-quality ecosystems greater than $50 \%$ accounted for $86.1 \%$. In particular, a large tract of primeval forests is distributed on the southeastern Tibet Plateau, with the forest coverage rate reaching more than $80 \%$.

\subsection{Regional differentiation in ecological conservation at the county scale}

Based on the number of ecological conservation programs in each county (Figure 3), we can see that counties with one or fewer programs are mostly distributed in Hebei, Shandong, 


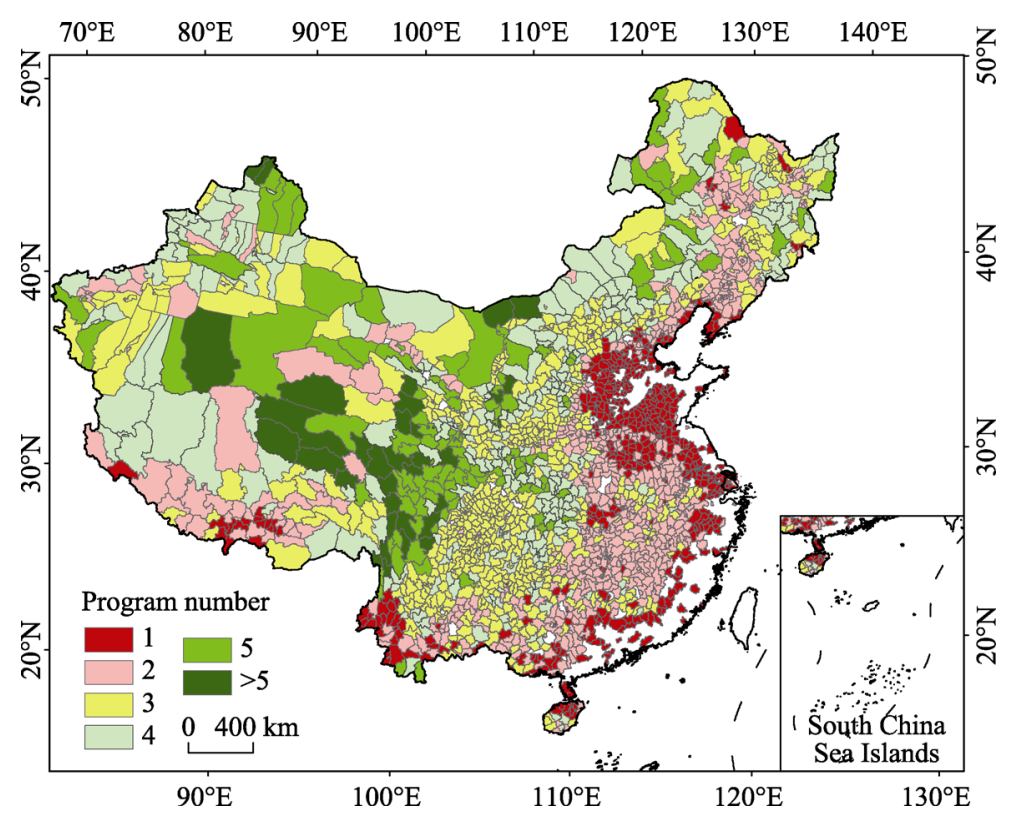

Figure 3 The distribution of the number of major ecological conservation programs at the county level in China

Jiangsu, Zhejiang, Fujian and other eastern coastal areas. The counties with two programs are concentrated in central China as well as in the northeastern region and Tibet and Xinjiang. The counties with three programs are mainly distributed in western China, especially in southwestern China and on the Loess Plateau. The counties with four programs primarily occur in Inner Mongolia, northern Xinjiang and northern Tibet. The counties with five or more programs are located in the Three-River Source Region, the Qilian Mountains, southeastern Tibet, western Sichuan province, and southern Xinjiang.

China's ecological conservation measures focus on afforestation, grass planting, enclosures, and others. In terms of spatial distribution, integrated afforestation, grass planting and enclosures were implemented in the eastern and central parts of Inner Mongolia, north of the Tianshan Mountains, the upstream of the Tarim River, the Ordos Plateau, the Heihe River Basin, the Shule River Basin, and the western bank of the Yellow River. Grassland conservation measures of enclosure establishment and rotational grazing were mostly applied in Inner Mongolia, Qinghai, Tibet, Xinjiang and other grassland areas. Afforestation and enclosure measures were widely used in forest nursery areas and GFGP regions.

\subsection{The dynamics of high-quality ecosystem and vegetation coverage over recent 15 years}

From 2000 to 2015 (Figure 4), the proportional area of high-quality ecosystems in 1512 counties in China increased, especially on the Loess Plateau and in the upper and middle reaches of the Yangtze River Basin. In terms of single ecosystem types, the proportional area of forest increased in 1722 counties, the proportional area of high-coverage grassland increased in 1522 counties, and the proportional area of wetland increased in 2214 counties. The forested area on the Loess Plateau has significantly increased, and the ecological environment changed from "overall deterioration and local improvement" to "overall improvement and local benign cycle", which indicates the positive effects of the ecological conser- 
vation and restoration programs. The area of cultivated land along the upper and middle reaches of the Yangtze River declined; however, the forested area obviously increased, and the wetland area grew slightly, especially in the Three Gorges Reservoir and the Wujiang River Basin.
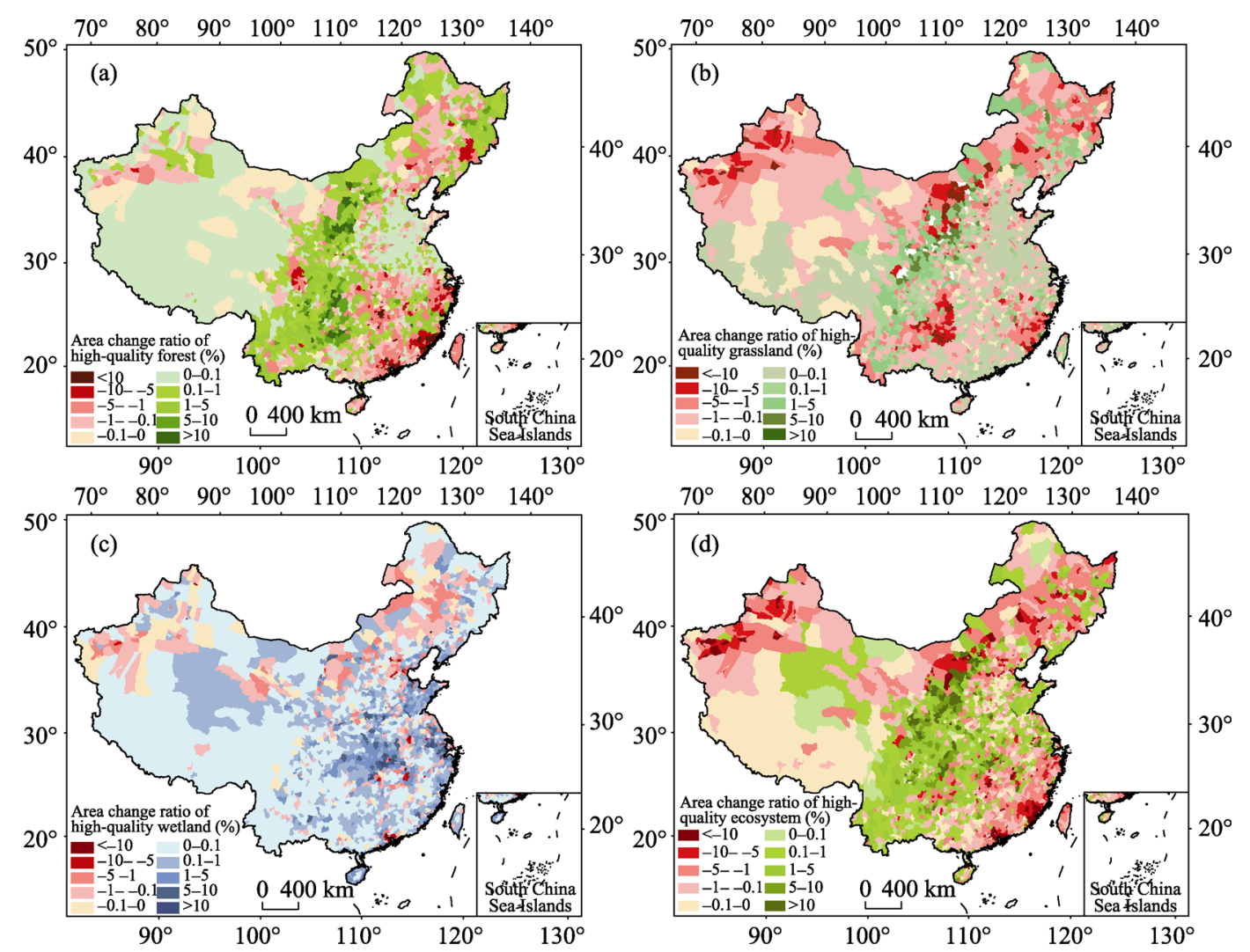

Figure 4 Proportional change in the area of forest (a), grassland (b), wetland (c) and all high-quality ecosystems (d) at the county level in China during 2000-2015

At the same time, the proportional area of high-quality ecosystems in 1347 counties in China decreased over the past 15 years, especially in northwestern Xinjiang, southeastern coastal regions, northeastern China, and eastern Inner Mongolia. In these regions, the proportional area of forest decreased in 1137 counties, the proportional area of high-coverage grassland decreased in 1337 counties, and the proportional area of wetland decreased in 645 counties. Urbanization in the southeastern coastal regions has led to a decline in the area of forest and grassland. The area of forest has significantly increased in northwestern Xinjiang, central and eastern Inner Mongolia, and northeastern China, but the area of grassland and wetland has obviously decreased, which has resulted in a decrease in the percentage of high-quality ecosystems. In terms of the background climate, those changes in area are not conducive to upgrading the region's ecosystem quality and service capacity.

From 2000 to 2015, the changes in vegetation coverage at the county level in China showed significant regional differentiation (Figure 5). The vegetation coverage increased significantly in the counties of the Loess Plateau, Huang-Huai-Hai Plain, Beijing-Tianjin-Hebei, and Sichuan-Guizhou-Chongqing, and Guangdong-Guangxi provincial-level 

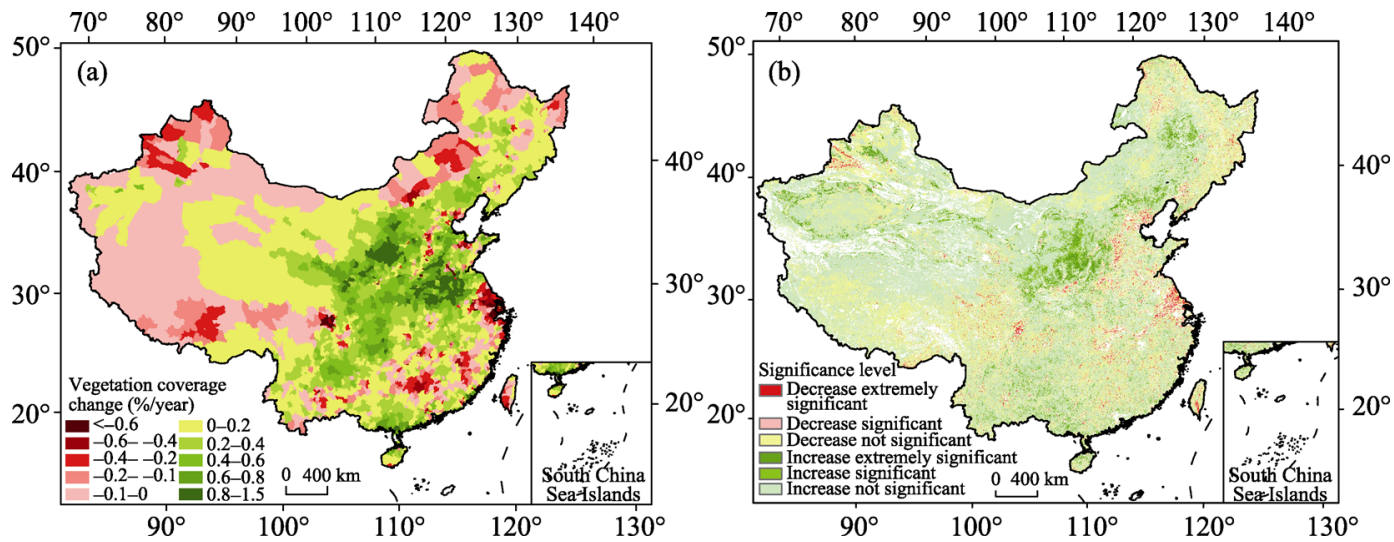

Figure 5 Changes in vegetation coverage (a) and its significance level (b) at the county scale in China during $2000-2015$

areas. Among them, the increasing trend in vegetation coverage is most obvious in the Loess Plateau and is particularly significant in the Qinling-Daba Mountains and the Funiu Mountains, with annual increasing rates of $0.8 \%$ to $1.5 \%$. It also showed a more obvious upward trend in the Huang-Huai-Hai Plain, Yimeng Mountains and Dabie Mountains, with annual increases of approximately $0.4 \%$ to $0.8 \%$. In contrast, the decline in vegetation coverage was mainly concentrated in the counties of northern Xinjiang, central Tibet, central and eastern Inner Mongolia and other arid and semi-arid regions, and the urban expansion area of the Yangtze River Delta. In the northern part of Xinjiang and central and eastern Inner Mongolia, the vegetation coverage decreased by more than $0.6 \%$. Due to the high level of urbanization in recent years, vegetation coverage in the middle and lower reaches of the Yangtze River also showed a decreasing trend, especially in the Yangtze River Delta and Hunan, Jiangxi and Zhejiang provinces.

\subsection{Regional suitability of ecological conservation at the county scale}

The relationships between the number of ecological conservation programs and the changes in ecological indicators (Figure 6) show that the proportional change in area of high-quality ecosystems of the total area of high-quality ecosystems in a county is higher in the counties that implemented three to five ecological conservation programs; however, it was relatively
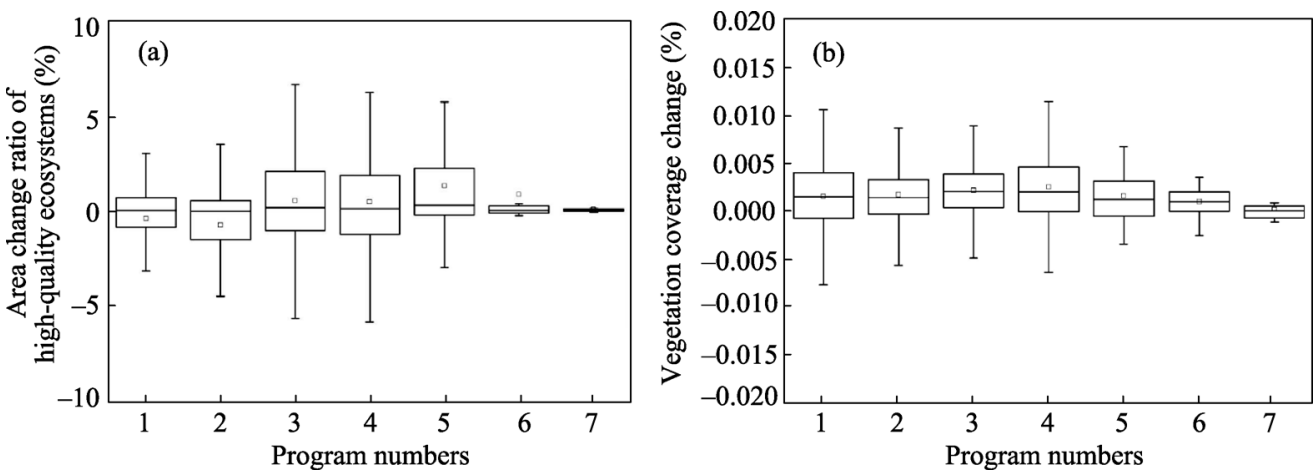

Figure 6 The relationships between the number of ecological conservation programs and the changes in high-quality ecosystems (a) and vegetation coverage (b) 
lower in counties that had implemented fewer than three or more than five programs. In particular, the increasing trend of the annual average vegetation coverage is the highest in the counties where four ecological conservation programs had been implemented. The larger the number of programs, the more the vegetation coverage had declined. Therefore, there was no positive correlation between the number of programs and improvement in ecological status based on high-quality ecosystems and vegetation coverage.

Climate change and ecological conservation simultaneously affect regional ecosystem changes, of which the former is the most important. Therefore, ecological conservation measures need to adapt to the regional background climate. Inappropriate measures have negative impacts on regional ecosystems. Taking the arid oasis in the Shule River Basin, in the northern foot of the Tianshan Mountains and the upper reaches of the Tarim River, as an example, due to its relatively high amounts of alpine ice and snow melt water, the ecosystem is dominated by low- and medium-coverage grassland, and the counties have implemented more than three ecological conservation programs. Grassland conservation has had a small effect; however, afforestation has not changed the ecological degradation situation and has even led to further deterioration (Figure 7).
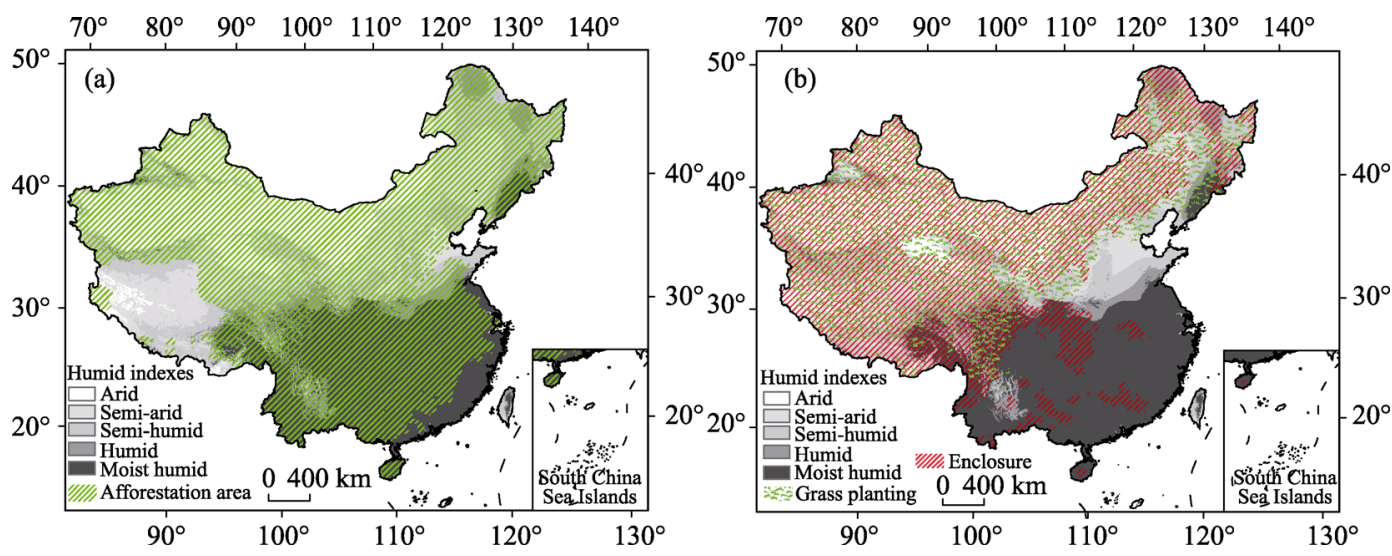

Figure 7 The distribution of afforestation (a) and grass planting and enclosures (b)

\section{Discussion and conclusions}

In this paper, the role of ecological conservation programs in ecosystem changes at the county scale in China was evaluated by analyzing changes in high-quality ecosystems and vegetation coverage over the last 15 years. The results show that there are no positive correlations between the number of ecological conservation programs and the improvement of indicators of ecological status. First, there are zonal differences in the distribution of high-quality ecosystems in China. The percentages of high-quality ecosystems are greater than $50 \%$ in northeastern China, the southern subtropical zone and the southeastern Qinghai-Tibet Plateau. However, the percentages are lower than $20 \%$ in northwestern China, the southwestern karst zones, and the North China Plain. Second, the ecological conservation programs in recent decades have mostly been implemented in the typical ecologically fragile areas, such as the TRSR, southeastern Tibet, western Sichuan, the Qilian Mountains, and southern Xinjiang, where an average of nearly five programs have been implemented at the 
county scale. Over the past 15 years, the proportional area of high-quality ecosystems increased in approximately $53 \%$ of China's counties. The vegetation coverage at the county scale increased significantly in the Loess Plateau, Huang-Huai-Hai Plain, Beijing-Tianjin-Hebei, and Sichuan-Guizhou-Chongqing, and Guangxi-Guangdong provincial-level areas. However, the vegetation coverage has declined in northern Xinjiang, central Tibet, central and eastern Inner Mongolia, and the Yangtze River Delta, indicating that climate change plays a leading role among the factors affecting regional ecosystem changes (Yue et al., 2013; Lü et al., 2015). Therefore, ecological conservation should first consider the distribution pattern of high-quality ecosystems, and project measures, such as afforestation, should follow the laws of nature under the background of climate change.

Future ecological conservation programs should first determine the spatial scope needed for conservation and restoration at the macro level to carry out unified program planning and project implementation according to the laws of regional differentiation and the regional suitability based on the distribution of ecosystems in China to reduce unwanted program duplication or dispersion. Targeted conservation should be designed for different regions. For counties with a proportional area of high-quality ecosystems greater than $50 \%$, the main task is to protect high-quality ecological resources and to give priority to the implementation of ecological compensation while taking into account the effects of long-term ecological conservation. For counties in which high-quality ecosystems have significantly increased after the implementation of ecological conservation programs or in which ecological degradation has been effectively curbed, conservation programs should focus on the consolidation of the effects of long-term ecological conservation by investing fixed funds and implementing regular monitoring and evaluation and then taking into account the protection of high-quality ecosystems. For counties with several ecological conservation programs but fewer ecological effects and the need for further improvement, we should avoid the problems of dispersing the implementation of multiple ecological conservation programs and promote the integration of multiple programs in planning to integrate and enhance those scattered programs with limited effectiveness and combine various funds to improve the efficiency of capital.

In the process of the allocation of ecological conservation funds from the central government to local financial departments, on the one hand, in order to balance the relationships between the parties, the provincial finance departments tend to reallocate the funds, resulting in the reduction of funds for some of the counties. On the other hand, there are problems in expanding fund use, undefined compensation policies, and departmental apportionment in some areas, thus greatly reducing the efficiency of the use of compensatory funds and resulting in no obvious effects. In addition, the percentage of transfer payment funds used for ecological conservation is lower in counties. When using the funds, most local governments focus on the local financial gap and population and do not have enough funds for ecological conservation. Therefore, the mechanism used to evaluate the performance of a county's government needs to be linked with the effectiveness of ecological conservation. Based on the monitoring and assessment of the effects of ecological conservation at the county scale, scientific incentive, reward and punishment mechanisms should be established to assess the input of funds and their ecological benefits for ecological conservation. 
In this study, the effects of ecological conservation were assessed at the county scale using the indexes of high-quality ecosystem and vegetation coverage, which can provide a scientific basis for the assessment of a county's ecological environment, the approval of ecological protection funds, and the planning and implementation of ecological conservation programs. Our study differs from the qualitative assessment of performance based on ecological GDP or GEP (Liu et al., 2011) and differs from the quantitative description of graded evaluation using a single index (Liu et al., 2010; Liu et al., 2012). It also differs from a comprehensive evaluation, which may mask the actual effects (Li et al., 2014). The uncertainties of this study are mainly reflected in two aspects: 1) the definition and classification of high-quality ecosystems. For example, commercial plantations, such as eucalyptus, rubber and other economic forests, have the characteristics of high resource consumption and disturbance of the ecosystem through management but have lower ecological effects, so they should not be classified as high-quality ecosystems. However, because of the difficulties of acquiring spatial information, they were not considered in this study. 2) It is difficult to identify which specific programs increased or decreased ecological effects at the county scale based on facilitation or stress. Which ecological conservation programs have positive effects, and which are ineffective? Which programs can be combined to produce significant ecological effects? Such questions require us to further discuss the effectiveness of specific programs by combining different methods.

\section{References}

Allen R G, Pereira L S, Raes D et al., 1998. Crop Evapotranspiration: Guidelines for Computing Crop Water Requirements. FAO Irrigation and Drainage Paper 56. Rome: United Nations Food and Agriculture Organization, 15-86.

Deng L, Liu G B, Shangguan Z P, 2014. Land-use conversion and changing soil carbon stocks in China's 'Grain-for-Green' Program: A synthesis. Global Change Biology, 20(11): 3544-3556.

Fu B J, 2010. Trends and priority areas in ecosystem research of China. Geographical Research, 29(3): 383-396. (in Chinese)

Huang L, Cao W, Gong G L et al., 2016. Spatial and temporal variations in ecosystems in the three northern regions of China, 2000-2010. Acta Ecologica Sinica, 36(1): 107-117. (in Chinese)

Li G P, Liu Q, Zhang W B et al., 2014. Transfer payment system in the national key ecological function area and the ecological environmental quality: Empirical study based on the countryside data of Shaanxi Province. Journal of Xi'an Jiaotong University, 34(2): 27-31. (in Chinese)

Li S D, Zhai H B, 2002. The comparison study on forestry ecological projects in the world. Acta Ecologica Sinica, 22(11): 1976-1982. (in Chinese)

Li S S, Yan J P, Wan J, 2013. Response of vegetation restoration to climate change and human activities in Shaanxi-Gansu-Ningxia Region. Journal of Geographical Sciences, 23(1): 98-112.

Liu H J, Zhang J H, He L H et al., 2010. Analysis of the status and spatial distribution patterns of county-level eco-environmental quality of China. Environmental Monitoring of China, 26(6): 62-65. (in Chinese)

Liu J, Diamond J, 2005. China's environment in a globalizing world. Nature, 435(7046): 1179-1186.

Liu J Y, Kuang W H, Zhang Z X et al., 2014. Spatiotemporal characteristics, patterns, and causes of land-use changes in China since the late 1980s. Journal of Geographical Sciences, 24(2): 195-210.

Liu J Y, Xu X L, Shao Q Q, 2008. Grassland degradation in the "Three-River Headwaters" region, Qinghai Province. Journal of Geographical Sciences, 18(3): 259-273.

Liu R, Wang S X, Zhou Y et al., 2012. Ecological environment condition evaluation mode of county region based 
on remote sensing techniques. China Environmental Science, 32(1): 181-186. (in Chinese)

Liu Y S, Liu Y, Chen Y F, 2011. Territorial multi-functionality evaluation and decision-making mechanism at county scale in China. Acta Geographica Sinica, 66(10): 1379-1389. (in Chinese)

Lü Y, Zhang L, Feng X et al., 2015. Recent ecological transitions in China: Greening, browning, and influential factors. Scientific Reports, 5(1): 8732.

Ministry of Environmental Protection of the People's Republic of China (MEP-PRC), 2016. The 13th Five-Year Planning Outline of National Ecological Protection. (in Chinese)

Ministry of Environmental Protection of the People's Republic of China (MEP-PRC), Chinese Academy of Sciences (CAS), 2017. Investigation and Assessment of National Ecological Environment by Remote Sensing for Ten Years from 2000 to 2010. Beijing: Science Press. (in Chinese)

Ministry of Finance of the People's Republic of China (MF-PRC), 2011. Notice on the Issuance of the Transfer Payment Method for National Key Ecological Function Areas. (in Chinese)

Shao Q Q, Fan J W, Liu J Y et al., 2017. Effects of an ecological conservation and restoration project in the Three-River Source Region, China. Journal of Geographical Sciences, 27(2): 183-204.

Shao Q Q, Liu J Y, Huang L et al., 2013. Integrated assessment on the effectiveness of ecological conservation in Sanjiangyuan National Nature Reserve. Geographical Research, 32(9): 1645-1656. (in Chinese)

State Forestry Administration of the People's Republic of China (SFA-PRC), 2008. Development report of the Three-North Shelter Forest System in the Past 30 Years (1978-2008). Beijing: China Forestry Publishing House. (in Chinese)

State Forestry Administration of the People's Republic of China (SFA-PRC), 2016a. National Report on Ecological Benefit of Grain for Green Program (2015). Beijing: China Forestry Publishing House. (in Chinese)

State Forestry Administration of the People's Republic of China (SFA-PRC), 2016b. National Report on Ecological Benefit of Natural Forest Resources Protection Program in Key State-owned Forest Area in Northeast China and Inner Mongolia (2015). Beijing: China Forestry Publishing House. (in Chinese)

Thornthwaite C, 1948. An approach toward a rational classification of climate. Geographical Review, 38(1): 55-94.

Wang B, Zhang G H, Liu G B et al., 2012. Ecological and environmental evaluation for water and soil loss comprehensive harness in loess hilly region. Transactions of the Chinese Society of Agricultural Engineering, 28(20): 150-161. (in Chinese)

Wang L, Fu B J, Lv Y H et al., 2010. Spatio-temporal variations of vegetation cover in northern Shaanxi province under the background of ecological restoration. Chinese Journal of Applied Ecology, 21(8): 2109-2116. (in Chinese)

Wang S, Fu B J, Piao S L et al., 2015. Reduced sediment transport in the Yellow River due to anthropogenic changes. Nature Geoscience, 9: 38-41.

Wang T, 2004. Progress in sandy desertification research of China. Journal of Geographical Sciences, 14(4): $387-400$.

Yue T X, Zhao N, Ramsey R D et al., 2013. Climate change trend in China, with improved accuracy. Climatic Change, 120(1): 137-151.

Zhang Y M, Zhao S D, 2007. The condition and trends of the world's ecosystems. Advances in Earth Science, 22(4): 403-409. (in Chinese)

Zhuo L, Cao X, Chen J et al., 2007. Assessment of grassland ecological restoration project in Xilin Gol Grassland. Acta Geographica Sinica, 62(5): 471-480. (in Chinese) 